\title{
Sposàrsi a Franca: tendências da nupcialidade entre imigrantes italianos no interior paulista, $1885-1930^{*}$
}

\author{
José Victor Maritan Gonçalves *
}

\begin{abstract}
Em consonância com os estudos em Demografia Histórica e História da Família, este artigo visa a resgatar aspectos relativos à nupcialidade vivenciada pelos italianos e seus descendentes no município de Franca, interior do estado de São Paulo. A reflexão é corroborada pela historiografia recente que aponta a expansão da economia cafeeira no interior paulista como responsável por alterações no panorama demográfico por meio da atração de uma imigração internacional em massa, cujos impactos foram sentidos em diferentes espaços de ação, na família, nas relações matrimoniais, na etnicidade e integração desses grupos na sociedade brasileira entre o final do século XIX e as primeiras décadas do século XX. Combinando metodologias seriais e de microanálise para explorar os dados disponíveis nos registros de matrícula da Hospedaria de Imigrantes de São Paulo e assentos de casamento do Registro Paroquial do Arquivo da Cúria Diocesana de Franca (1885-1930), abre-se caminho para enriquecer o universo de interpretações sobre a nupcialidade nos municípios atingidos pela imigração internacional de italianos. Esse artigo examina os impactos das variáveis imigratórias nos padrões de casamento dos italianos no município e resgata aspectos da endogamia desse grupo, favorecida pelos respectivos contextos e bagagens culturais que conduziram o processo imigratório por eles vivenciado.
\end{abstract}

Palavras-chave: Imigração italiana. Nupcialidade. Micro-história.

\footnotetext{
* O presente trabalho foi realizado com apoio da Coordenação de Aperfeiçoamento de Pessoal de Nível Superior - Brasil (Capes), código de financiamento 001.

** Faculdade de Ciências Humanas e Sociais da Universidade Estadual Paulista “Júlio de Mesquita Filho” (Unesp), FrancaSP, Brasil (jvm.goncalves@unesp.br; https://orcid.org/0000-0001-9954-0733).
} 


\section{Introdução}

Em Apologia da História, Marc Bloch (2002) advertiu que, quanto mais profunda fosse uma pesquisa, mais diversificado deveria ser o conjunto de fontes usadas para dar luz às evidências. Na presente pesquisa, a combinação de métodos quantitativos e qualitativos foi aplicada às práticas de nupcialidade dos italianos da Paróquia Nossa Senhora da Conceição de Franca no período compreendido entre 1885 e 1930. 0 objetivo foi resgatar aspectos relativos ao comportamento da nupcialidade desses grupos de imigrantes e confirmar a hipótese de que a endogamia era regulada conforme a organização social do grupo e refletia as condições do processo imigratório e seus respectivos contextos e bagagens culturais.

Também se busca apontar as possibilidades de investigação para a presença italiana no interior paulista a partir da identificação dos indivíduos, examinando os impactos das variáveis imigratórias nos padrões de casamento dos italianos em Franca, no sentido de resgatar aspectos relativos à origem regional da população presente nesse mercado matrimonial, as oportunidades de casamento e as redes imigratórias formadas nas localidades de origem e destino. Os estudos sobre o tema realizados por Maria Silvia Bassanezi e Oswaldo Truzzi servirão de base para o diálogo por meio de análises demográficas e sobre as estruturas sociais em outras localidades do estado de São Paulo, principalmente para demonstrar a hipótese de que a endogamia era regulada pelo espaço social e geográfico onde os nubentes estavam inseridos, ou seja, o estreito contexto da fazenda cafeeira. 0 rumo tomado pelas famílias favorecia o encontro de parceiros da terra de origem ou conhecidos durante a imigração, cujas uniões reforçavam vínculos de amizade e conterraneidade responsáveis por criar extensas redes entre italianos e seus descendentes.

Este artigo está dividido em três partes. Inicialmente, são apresentadas a documentação utilizada como fonte de pesquisa para o tema proposto e a metodologia aplicada, com suas limitações e possibilidades. A seguir, descrevem-se a localidade estudada e as transformações demográficas ocorridas com a imigração em massa. Por fim, mediante a análise empírica das fontes paroquiais, são abordados os resultados alcançados no estudo sobre o mercado matrimonial dos imigrantes italianos em Franca.

\section{Arrolando a população ítalo-brasileira em Franca}

Os livros de matrícula da Hospedaria de Imigrantes de São Paulo e os registros paroquiais constituem fontes seriais de grande importância para o estudo sobre a presença estrangeira no estado de São Paulo. Em suas páginas, a população era identificada individualmente pelo nome, permitindo explorações em várias direções para reconstituir a história social.

As fontes de natureza nominativa permitem o cruzamento entre si e com outras fontes conforme as oportunidades oferecidas pela documentação e os objetivos da pesquisa. A partir da década de 1970, despontou no debate historiográfico italiano uma leitura do 
social a partir do método onomástico e da análise micro-histórica, que permitiram "uma reconstituição do vivido impensável noutros tipos de historiografia” (GINZBURG, 1989, p. 177-8), a partir da recomposição de trajetórias individuais e de grupo por intermédio da documentação paroquial e civil. 0 nome como fio condutor levou a um âmbito de investigação circunscrito, no qual as séries documentais permitiram encontrar os indivíduos e identificar seus grupos em diversos contextos sociais. A identificação nominativa possibilitou reconstituir "a imagem gráfica do tecido social em que o indivíduo está inserido"(GINZBURG, 1989, p. 175), orientando os historiadores à exploração qualitativa das fontes seriais, em perspectiva tanto demográfica quanto sociocultural (BASSANEZI, 2009).

Os registros de matrícula de imigrantes entrados na Hospedaria de São Paulo, entre 1882 e 1930, formam um conjunto documental já informatizado em uma base de dados, que pode ser livremente acessado no acervo on-line do Memorial do Imigrante. 0 conteúdo desses arrolamentos de imigrantes apresenta os seguintes campos: nome, sobrenome, nacionalidade, profissão, idade, religião, sexo, grau de instrução, estado civil, destino (fazenda, nome do fazendeiro), composição familiar, nome do navio e data de entrada na Hospedaria.

Embora nem todas as listas de imigrantes tivessem essas informações devidamente anotadas, elas são imprescindíveis para um estudo quantitativo sobre a entrada massiva de imigrantes e os impactos sobre a composição populacional no estado de São Paulo. Os dados extraídos desses livros de matrícula são os únicos capazes de quantificar as cifras de entrada de italianos, além de revelar um retrato bastante fiel das famílias imigrantes quanto ao número médio de pessoas que compunham cada unidade familiar, se imigravam mais homens ou mulheres, adultos ou crianças.

O uso desse tipo de documentação só foi possível graças ao levantamento e cruzamento nominativo com os dados seriais coletados por meio da exploração dos registros paroquiais. 0 primeiro passo foi a criação de um banco de dados ${ }^{1}$ conforme a metodologia proposta por Fleury e Henry (1977) para reconstituição de famílias, cruzando as informações coletadas em 21.251 registros de batismos, 4.611 de casamentos e 2.288 de óbitos de ítalo-brasileiros presentes no município de Franca, ${ }^{2}$ resultando em 8.885 fichas de família. Depois de identificar os indivíduos nas fontes paroquiais, foi realizada a busca pelo registro de entrada dessas famílias no país no banco de dados do Memorial do Imigrante, que conta com 544.613 pessoas catalogadas com a nacionalidade italiana.

0 emprego dos registros paroquiais foi adotado tendo em vista os objetivos que nortearam a reconstituição dos padrões de casamento e a investigação sobre a origem regional da população presente no mercado matrimonial local, resgatando aspectos da história social e demográfica dos italianos no âmbito da economia cafeeira paulista.

\footnotetext{
${ }^{1}$ Após o levantamento inicial da documentação que seria coletada, foi elaborada uma base de dados utilizando Excel, o editor de planilhas da Microsoft. Planejar uma planilha única para todas as fontes foi uma maneira de automatizar os procedimentos e facilitar a operação artesanal de lançar e cruzar os dados nominativos de uma só vez.

${ }^{2}$ Esse banco de dados compreende os registros do período de 1885 a 1944.
} 
Em suma, as informações constantes nos registros paroquiais de matrimônio são: data e local do casamento; nomes, idades e local de nascimento dos cônjuges; e nomes dos pais e testemunhas. Esses dados coletados no Arquivo da Cúria Diocesana de Franca foram digitados em tabelas com esses campos para facilitar a análise das informações e o posterior cruzamento com outras fontes.

0 interesse em investigar o comportamento matrimonial desses grupos imigrantes esbarrou na ausência de informações nas fontes consultadas, que podem interferir na análise quantitativa sobre a entrada de italianos no mercado matrimonial de Franca: a falta de dados, nos livros de matrícula da Hospedaria de Imigrantes, sobre o estado conjugal e o destino indicado. Para driblar essa deficiência, foram considerados os responsáveis pelo movimento nesse mercado matrimonial exclusivamente as crianças e jovens imigrantes com até 20 anos de idade. Optamos por esse coorte sabendo que, dentre os imigrantes italianos com mais de 21 anos, também havia homens e mulheres solteiros, casados e viúvos suscetíveis de se casarem.

Outro desafio ao se pensar na análise demográfica histórica é realizar o encadeamento genealógico dos indivíduos. Embora o processo de cruzamento nominativo revela-se complexo e demorado, o estudo com a população ítalo-brasileira é menos difícil do que os levantamentos de outras populações, como a luso-brasileira. Em nosso caso, uma série de problemas de identificação não existiram, tais como a falta de regras para transmissão dos nomes de família, alteração e/ou inversão dos nomes e sobrenomes, mulheres sem sobrenomes, alta incidência de homônimos. Nesse sentido, o único problema encontrado referiu-se à existência de segundos nomes, mas a experiência adquirida no decorrer da pesquisa foi tornando mais eficientes a localização e o cruzamento nominativo.

A identificação dos indivíduos e o cruzamento das fontes foram efetuados no ato do levantamento, permitindo acompanhar as famílias e iluminar sua rede de relações. Embora nossa proposta pretendesse uma investigação de tipo serial, a reconstituição dessas redes de imigrantes desembocou numa série de estudos de casos, tais como dos italianos provenientes das regiões do Vêneto, da Lombardia e do Abruzo.

\section{Italianos em Franca}

No século XVIII, a queda no vigor da atividade mineradora e a abertura de novas áreas para exploração de outras atividades econômicas mobilizaram pessoas e famílias (RODARTE, 2008, p. 76) para as pastagens do norte da província de São Paulo (MARCílIO, 2000, p. 72). Posteriormente, o café recolocou o Brasil no mercado internacional e tornou o interior paulista uma rota privilegiada para os imigrantes italianos, que buscavam um destino para sobreviver fora do seu mercado saturado de trabalho (FRANZINA, 2006).

0 munícipio de Franca, fundado em 1805, tornou-se novamente o destino de famílias inteiras de imigrantes atraídos pelas novas oportunidades de trabalho, que fugiram do 
excedente demográfico camponês que estava colocando em situação de miserabilidade tanto os braccianti ${ }^{3}$ e os assalariados, quanto os pequenos proprietários, colonos e meeiros.

As últimas décadas do século XIX foram marcadas pela entrada maciça de imigrantes estrangeiros atraídos para o trabalho na faina do café. Enquanto a Itália já apresentava altos índices de saída de pessoas para a América desde 1876, o município de Franca só seria atingido por essa corrente imigratória na década seguinte, praticamente às vésperas da abolição dos escravos. Além da desagregação do sistema escravista, a expansão da rota do café pelo interior paulista envolveu o município somente após a instalação do ramal da Companhia Mogiana de Estradas de Ferro e a escassez da terra roxa, considerada mais fértil para as lavouras cafeeiras. Esses fatores contribuíram para o fortalecimento tardio da chegada maciça de imigrantes ao município e uma caracterização regional particular.

Durante todo o século XIX, a pecuária, a produção voltada para o abastecimento interno, o comércio do sal e a tecelagem foram as principais atividades econômicas desenvolvidas em Franca. A produção de café era incipiente e as plantações locais não permitiam enquadrar o município como agroexportador, embora o comércio do sal garantisse sua posição como entreposto comercial. Na década de 1880, o cultivo do café que estava avançando pela zona central do estado de São Paulo, em torno de Campinas, para as terras roxas do oeste, alcançou a região denominada Alta Mogiana, que na ocasião era composta por grandes latifúndios detidos por poucos proprietários. Mesmo após a chegada dos trilhos da Mogiana em 1887, o plantio de café não gerou um domínio monocultor, passando a ser mais uma das atividades dessa economia diversificada.

No Recenseamento Geral do Império de 1872, a população do município de Franca ${ }^{4}$ era de 21.419 habitantes, equivalendo a 2,56\% dos moradores da Província de São Paulo. A Paróquia Nossa Senhora da Conceição de Franca, que corresponde, aproximadamente, ao atual município de Franca, contabilizava 8.248 habitantes, apresentando uma pequena população de estrangeiros, que atingia quase $2 \%$ do total, revelando o início de alterações na estrutura e composição populacional. Essa parcela de estrangeiros era composta por africanos livres e escravizados e europeus provenientes de Portugal, Itália, Alemanha e França. Os africanos compunham $80 \%$ dos estrangeiros, sendo livres apenas $7 \%$ dessa parcela. Entre os europeus, os portugueses representavam $83,5 \%$, seguidos por $8 \%$ de italianos e $7 \%$ de alemães. Deve-se ressaltar que essa população era relativamente jovem, com idade média de 23 anos, apresentando um excedente de homens em relação às mulheres. ${ }^{5}$ Mais de $2 / 3$ de seus componentes eram solteiros, sendo a maior porção composta por crianças, que ultrapassavam $30 \%$ da população. ${ }^{6}$ Os casados compreendiam $23,85 \%$ dos moradores e havia ainda um pequeno número de viúvos (3,08\%).

\footnotetext{
${ }_{3} 0$ termo braccianti refere-se ao trabalhador agrícola contratado para breves períodos de trabalho.

${ }^{4} 0$ território de Franca abrangia as paróquias de Nossa Senhora da Conceição de Franca, Nossa Senhora do Carmo da Franca, Santa Barbara das Macaúbas, Santa Rita do Paraíso e Santo Antônio de Rifaina, atuais municípios de Franca, Ituverava, Patrocínio Paulista, Igarapava e Rifaina, respectivamente.

${ }^{5}$ A porcentagem de homens e mulheres estrangeiros era de $2,67 \%$ e $1,24 \%$, respectivamente.

${ }^{6}$ A população com até dez anos de idade era $30,36 \%$ e a de 11 a 15 correspondia a $12,68 \%$.
} 
Os dados do Censo de $1920^{7}$ mostram o aumento da população de Franca, associado ao crescimento vegetativo, à imigração e à migração interna e regional. Nesse ano, uma parte considerável dos habitantes era composta por estrangeiros, sendo o município que mais atraiu imigrantes dentro do antigo território francano no período imperial.

Esse afluxo de imigrantes representou um impacto na composição da população local, conforme se pode observar na Tabela 1, que mostra, em números absolutos e percentuais, como a proporção de contingentes populacionais se deslocaram significativamente em 48 anos. Na década de 1870 , os nascidos na Itália eram poucos em comparação aos nascidos em Portugal e somavam apenas sete pessoas, menos de $2 \%$ dos estrangeiros residentes. Aproximadamente meio século depois, o recenseamento de 1920 mostrou a presença de 2.889 italianos nesta localidade, representando $46,6 \%$ dos estrangeiros vivendo em Franca.

TABELA 1

Crescimento populacional, por nacionalidade e sexo Município de Franca - 1872-1920

\begin{tabular}{|c|c|c|c|c|c|c|c|c|c|}
\hline \multirow{3}{*}{ Ano } & \multicolumn{4}{|c|}{ Brasileiros } & \multicolumn{4}{|c|}{ Estrangeiros } & \multirow{3}{*}{ Total } \\
\hline & \multicolumn{2}{|c|}{ Homens } & \multicolumn{2}{|c|}{ Mulheres } & \multicolumn{2}{|c|}{ Homens } & \multicolumn{2}{|c|}{ Mulheres } & \\
\hline & N. abs. & $\%$ & N. abs. & $\%$ & N. abs. & $\%$ & N. abs. & $\%$ & \\
\hline 1872 & 10.851 & 50,0 & 10.143 & 48,0 & 298 & 1,0 & 127 & 1,0 & 21.419 \\
\hline 1920 & 19.226 & 43,0 & 18.878 & 43,0 & 3.449 & 8,0 & 2.744 & 6,0 & 44.308 \\
\hline
\end{tabular}

Fonte: Recenseamento de 1872; Recenseamento de 1920.

Nota: 0 valor total da população em 1920 corresponde à soma dos brasileiros, estrangeiros e 11 pessoas de nacionalidade ignorada.

Os italianos formavam o maior contingente imigrante no município no início do século $X X$, seguido pelos espanhóis que compunham $36,8 \%$ dos estrangeiros. Portugal, Turquia e Argentina também aparecem como países de origem de uma parcela considerável. Entretanto, sabendo que a Argentina foi destino de muitos imigrantes saídos da Itália, é possível que esses argentinos sejam filhos de italianos nascidos no percurso da imigração.

TABELA 2

Imigrantes estrangeiros, por país de origem, segundo sexo Município de Franca - 1920

\begin{tabular}{|c|c|c|c|c|c|c|c|c|c|c|}
\hline \multirow{2}{*}{ Sexo } & \multicolumn{4}{|c|}{ Europa } & \multicolumn{2}{|c|}{ América } & \multicolumn{2}{|c|}{ Ásia } & \multirow{2}{*}{ Ignorada } & \multirow{2}{*}{$\begin{array}{l}\text { Total } \\
\text { geral }\end{array}$} \\
\hline & Itália & Espanha & Portugal & Outros & Argentina & Outros & Japão & Turquia & & \\
\hline Homem & 1.531 & 1.275 & 392 & 83 & 31 & 7 & 12 & 114 & 4 & 3.449 \\
\hline Mulher & 1.358 & 1.006 & 225 & 49 & 31 & 3 & 16 & 56 & - & 2.744 \\
\hline Total & 2.889 & 2.281 & 617 & 132 & 62 & 10 & 28 & 170 & 4 & 6.193 \\
\hline
\end{tabular}

Fonte: Recenseamento de 1920.

A quantidade de italianos que passaram pelo município teria sido bem maior; contudo, até a realização do Recenseamento de 1920, muitos imigrantes se deslocaram para outras

\footnotetext{
$\overline{7}$ Nesse recenseamento o território do município compreendia as vilas de São José da Bela Vista, Cristais, Restinga, Ribeirão Corrente e Ponte Nova. As antigas paróquias pertencentes a Franca em 1872 já haviam se tornado municípios independentes. Ver a nota $\mathrm{n} .4$.
} 
regiões ou regressaram à terra natal. Além disso, entre 1889 e 1920, faleceram 1.587 pessoas oriundas da Itália no território francano (DI GIANNI, 1997, p. 68).

Os livros de matrícula da Hospedaria de Imigrantes mostram que, a partir de 1886, aproximadamente 1,5 mil italianos tiveram como destino o município de Franca. As informações contidas nesses livros revelam ainda que alguns italianos de lá saíram com destino às estações férreas e fazendas dentro do antigo território municipal de Franca: Boa Sorte, Cristais, Mandiú e Restinga.

A reconstituição de famílias também localizou a entrada de 2,7 mil pessoas, distribuídas em 471 famílias, com destino desconhecido ou para outras localidades, que em algum momento tiveram seus assentos vitais realizados na Paróquia Nossa Senhora da Conceição de Franca. 0 perfil desses grupos pode ser observado na Tabela 3.

TABELA 3

Imigrantes italianos provenientes da Hospedaria de Imigrantes, segundo destino Município de Franca - 1886-1928

\begin{tabular}{lccc}
\hline \multicolumn{1}{c}{ Destino } & Número de pessoas & Número de famílias & $\begin{array}{c}\text { Quantidade média de } \\
\text { pessoas por família }\end{array}$ \\
\hline Franca & 1.477 & 431 & 3,4 \\
Boa Sorte & 56 & 11 & 5,0 \\
Cristais & 6 & 1 & 6,0 \\
Mandiú & 79 & 24 & 3,2 \\
Restinga & 92 & 27 & 3,4 \\
Outras localidades & 1.097 & 222 & 4,9 \\
Desconhecido & 1.603 & 249 & 6,4 \\
Total & $\mathbf{4 . 4 1 0}$ & 965 & $\mathbf{4 , 5}$ \\
\hline
\end{tabular}

Fonte: Registros de Matrícula da Hospedaria de Imigrantes de São Paulo, 1886-1928.

As famílias vindas da Itália para trabalhar nas fazendas de café geralmente não ultrapassavam quatro ou cinco pessoas (BASSANEZI, 2019, p. 101). A média de componentes dos grupos familiares vindos diretamente para Franca era de 3,4 pessoas. Os dados coletados nos livros de matrícula da Hospedaria mostram que esses italianos imigraram durante 0 ciclo de vida familiar, com famílias de composição nuclear (apenas o casal) ou nuclear com filhos. A idade média ao se casar na Itália interferia diretamente na quantidade de membros dos grupos imigrantes, pois na década de 1880 os homens normalmente casavam-se depois do serviço militar (ALVIM, 1986, p. 30), em média aos 28,1 anos (RETTAROLI, 1990, p. 147), e as mulheres aos 24,1 anos.

O perfil obtido das famílias reconstituídas foi muito semelhante ao apurado por Bassanezi (2019) para os imigrantes destinados à fazenda Santa Gertrudes entre 1897 e 1902. Para Franca, a idade média correspondia a 38,5 anos para os homens, 34,2 anos para as mulheres e 8,9 anos para os filhos, médias similares às observadas para a fazenda: 37,4, 33,8 e 7,2 anos, respectivamente (BASSANEZI, 2019, p. 76). Tratava-se de famílias em pleno processo reprodutivo, portanto, com possibilidades de crescer em tamanho na comunidade de destino. 0 alargamento das bases da pirâmide etária e o maior contingente 
de homens traduzem o perfil da população imigrante, de composição familiar e em idade produtiva.

\section{GRÁFICO 1}

Pirâmides etárias dos imigrantes italianos provenientes da Hospedaria de Imigrantes, por sexo Município de Franca - 1886-1928
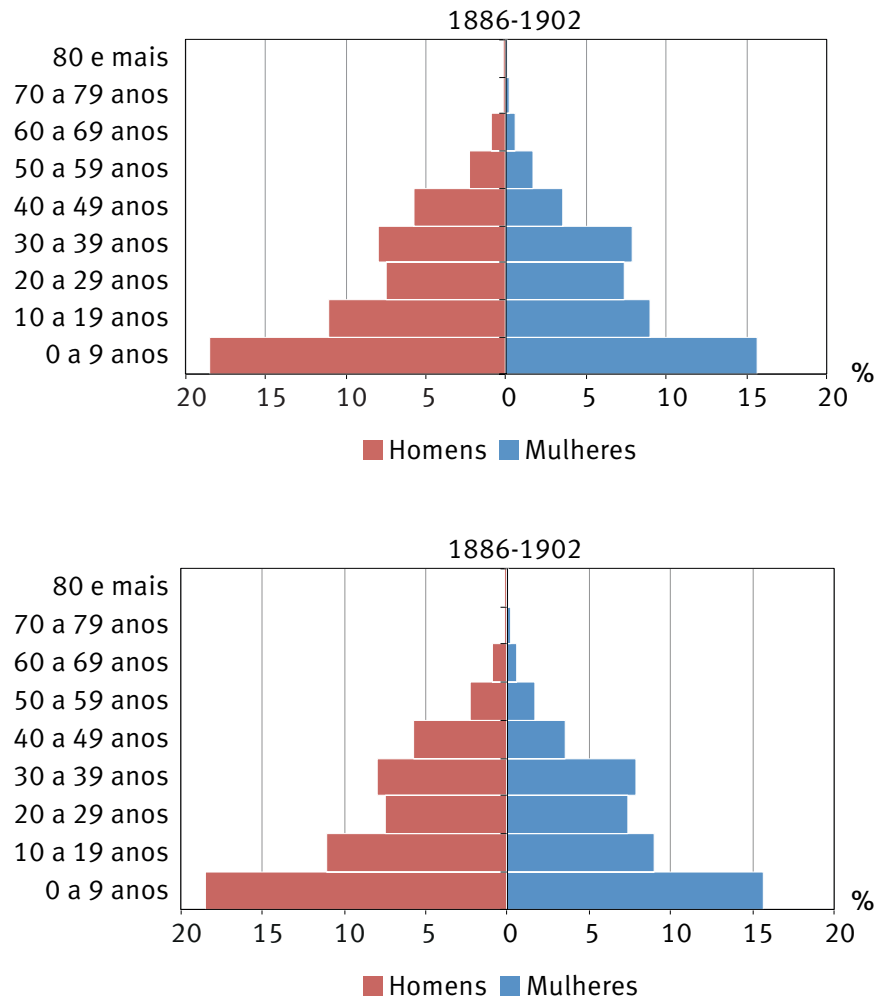

Fonte: Registros de Matrícula da Hospedaria de Imigrantes de São Paulo, 1886-1928.

No quadro da emigração transoceânica, embora marcada por uma elevadíssima presença de famílias (TRENTO, 1988, p. 31), influenciada pelo sistema de subsídio paulista (BASSANEZI, 2008, p. 37), a composição dos grupos era bastante diversa. Às vezes, imigravam três gerações de uma mesma família. Havia grupos compostos por um só cônjuge; famílias com todos os filhos ou só alguns deles; mulheres viúvas com filhos; chefes de família e seus filhos casados com seus respectivos cônjuges e filhos; além da presença de irmãos, sobrinhos e afilhados. Algumas vezes, o chefe de família também trazia os pais e, raramente, os sogros. 


\section{GRÁFICO 2}

Perfil dos imigrantes italianos provenientes da Hospedaria de Imigrantes Município de Franca - 1886-1928

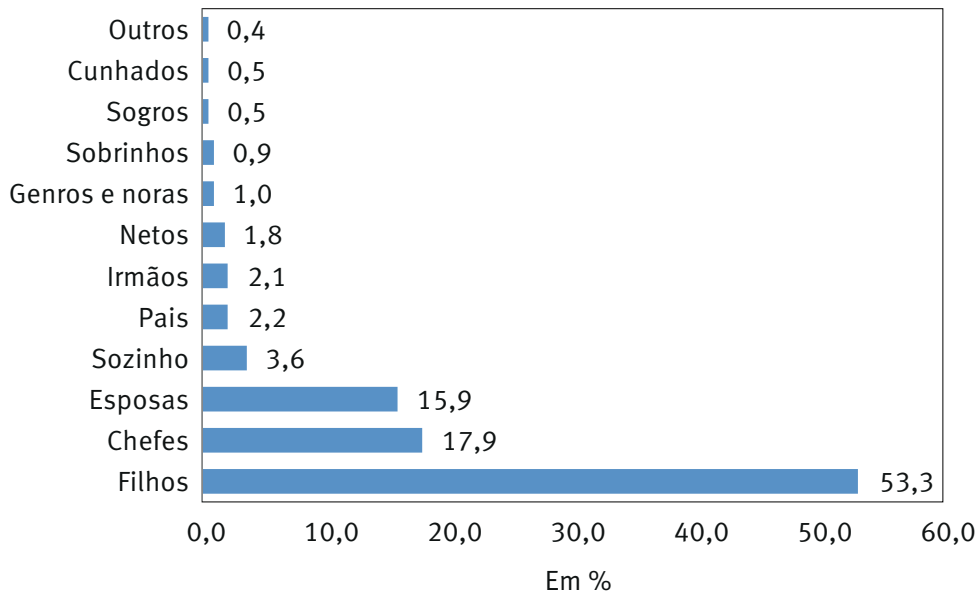

Fonte: Registros de Matrícula da Hospedaria de Imigrantes de São Paulo, 1886-1928.

Embora a maioria dos italianos que vieram trabalhar na cafeicultura paulista fosse braccianti, o que explica a grande quantidade de famílias jovens e em idade reprodutiva, as normas do governo brasileiro também foram responsáveis por moldar as características dessas famílias com a intenção de financiar a imigração de pessoas mais aptas para o trabalho. Para a obtenção de subsídios para a viagem era exigido que o grupo familiar tivesse, ao menos, um indivíduo do sexo masculino, com idade entre 12 e 45 anos, e só seriam incluídos na passagem da família os pais, avós, irmãos solteiros, cunhados e sobrinhos órfãos do chefe do grupo familiar. Os mecanismos de chamada de parentes também beneficiaram a vinda de mulheres casadas para reunirem-se aos maridos (HOLLOWAY, 1984).

TABELA 4

Imigração subvencionada de italianos, por local de destino, segundo tipos de subvenção Município de Franca - 1886-1928

\begin{tabular}{|c|c|c|c|c|c|c|c|c|}
\hline \multirow[t]{3}{*}{ Tipos de subvenção } & \multicolumn{6}{|c|}{ Local de destino } & \multirow{2}{*}{\multicolumn{2}{|c|}{ Total }} \\
\hline & \multicolumn{2}{|c|}{ Franca } & \multicolumn{2}{|c|}{$\begin{array}{c}\text { Outras } \\
\text { localidades }\end{array}$} & \multicolumn{2}{|c|}{ Nada consta } & & \\
\hline & Famílias & Pessoas & Famílias & Pessoas & Famílias & Pessoas & Famílias & Pessoas \\
\hline Decreto 1247 & 36 & 232 & 3 & 26 & - & - & 39 & 258 \\
\hline Outros decretos & 14 & 58 & - & - & - & - & 14 & 58 \\
\hline $\begin{array}{l}\text { Contratos entre o governo } \\
\text { do estado e companhias de } \\
\text { imigração }\end{array}$ & 25 & 117 & 5 & 30 & - & - & 30 & 147 \\
\hline $\begin{array}{l}\text { Imigração subsidiada pelo } \\
\text { governo provincial }\end{array}$ & 154 & 743 & 92 & 428 & 72 & 446 & 318 & 1.617 \\
\hline Sociedade promotora & 3 & 17 & 1 & 18 & 24 & 118 & 28 & 153 \\
\hline Total & 232 & 1.167 & 101 & 502 & 96 & 564 & 429 & 2.233 \\
\hline
\end{tabular}

Fonte: Registros de Matrícula da Hospedaria de Imigrantes de São Paulo, 1886-1928. 
A partir da década de 1890, a imigração subvencionada e os mecanismos de incentivo do governo foram responsáveis pela entrada de pelo menos 242 famílias com destino a Franca e outras 197 que chegariam ao município posteriormente, após experiências em outras localidades. Apenas no ano de 1901, os contratos entre o governo do estado e as companhias de imigração promoveram a chegada de 30 famílias, envolvendo um deslocamento de 147 pessoas, em regime de colonato, nas fazendas de café francanas. Embora o Decreto Prinetti, em 1902, tentasse proibir a arregimentação de italianos praticada pelo Brasil, outras medidas foram tomadas para que esses imigrantes continuassem a ter o país como destino. Posteriormente, o Decreto 1.247, de 19 de outubro de 1904, beneficiou a entrada de outras 39 famílias, totalizando mais 258 novos trabalhadores para as lavouras francanas.

Do ponto de vista metodológico, a utilização das fontes paroquiais permite traçar a trajetória desses grupos no território paulista, por meio da identificação nominativa e do cruzamento com os registros de matrículas de imigrantes. Deve-se ressaltar que, embora estejamos tratando de uma população em intenso deslocamento territorial, o método de reconstituição de famílias possibilitou localizar os registros de imigração de 4.414 italianos residentes em Franca, ou seja, 98,5\% dos italianos recenseados em 1920 e dos falecidos até o mesmo ano.

Esses registros revelam a composição por sexo e idade dos grupos de italianos que imigraram para Franca. Os dados disponíveis nesse corpus documental mostram que 2.425 homens e 1.989 mulheres italianos deixaram a Hospedaria e chegaram a Franca. Isto é, havia uma população masculina $9,8 \%$ maior do que a feminina. Embora a média de idade desses imigrantes, tanto dos homens quanto das mulheres, fosse de 20,7 anos, a quantidade de jovens com menos de 20 anos que poderiam fazer parte do mercado matrimonial local era de 1.340 homens e 1.081 mulheres. Tais números indicam que nessa comunidade étnica havia 1,2 homem para cada mulher. No Gráfico 1, a pirâmide etária da população imigrante mostra um formato típico do mundo imigrante da época, com um desequilíbrio a favor da população masculina e em idade produtiva, conforme a demanda por mão de obra voltada à cafeicultura (BASSANEZI, 2008, p. 54).

Em relação à época de chegada e à procedência regional desses grupos imigrantes, pode-se dizer que, em sua maioria, eram oriundos do norte da Itália. Os vênetos perfaziam mais da metade de todo o contingente, seguidos pelos lombardos. A distribuição regional desses imigrantes correspondia às épocas de expulsão no país de origem e de atração no ambiente de destino. A historiografia que trata da procedência geográfica mostra variações do fenômeno imigratório. Os vênetos e lombardos, pioneiros da imigração em massa, constituíram o maior contingente, enquanto os meridionais e toda a Itália central aderiram à imigração em outros momentos. Os meridionais tiveram maior participação entre os imigrantes com destino às ocupações urbanas e emigraram preferencialmente sem família, ao passo que os setentrionais tiveram uma elevadíssima composição familiar 
e correspondiam às preferências dos fazendeiros devido à sua parcimônia, frugalidade e docilidade (TRENTO, 1988, p. 41, 59-60).

Historicamente, o êxodo da região do Vêneto repeliu primeiramente os pequenos proprietários e arrendatários que sofriam com a transformação capitalista dos campos, as colheitas desfavoráveis e as calamidades naturais. Tais causas conjunturais do fenômeno emigratório no Vêneto configurou um movimento pioneiro das populações abundantes das áreas montanhosas, subalpinas e de colina de Belluno, Treviso, Vicenza e Udine, ${ }^{8}$ nas primeiras décadas após a unificação do território italiano. Em Franca, a presença significativa de vênetos nascidos na província de Rovigo revela uma atração de imigrantes tardia em relação às outras áreas do estado de São Paulo, pois o avanço da economia cafeeira pelas terras da Alta Mogiana se concretizou apenas às vésperas da abolição dos escravos. Ou seja, as províncias antes pouco atingidas pela situação migratória já conhecida há anos nos arredores agrícolas montanhosos, subalpinos e de colina contribuíram com significativo contingente de emigrantes para Franca.

No decorrer da década de 1880, os camponeses das províncias de Rovigo, Verona, Pádua e Veneza passaram a engrossar o contingente de emigrantes transoceânicos, influenciados pelos fenômenos ligados ao desenvolvimento capitalista da agricultura e aos abalos climáticos que atingiram a faixa da planície do rio Pó. Os imigrantes oriundos dessas províncias representaram $83,7 \%$ do total de vênetos residentes em Franca, o que permite afirmar que a procedência geográfica deve ser analisada mediante os fatores atrativos e as fases do êxodo italiano.

TABELA 5

Imigrantes italianos, segundo região de procedência Município de Franca - 1885-1930

\begin{tabular}{lrrr}
\hline \multicolumn{1}{c}{ Região } & Localização & \multicolumn{1}{c}{ N } & \multicolumn{1}{c}{$\%$} \\
\hline Vêneto & Norte & 1.345 & 55,5 \\
Lombardia & Norte & 245 & 10,1 \\
Abruzo & Centro & 137 & 5,6 \\
Emilia-Romanha & Norte & 127 & 5,2 \\
Lácio & Centro & 116 & 4,7 \\
Campania & Sul & 112 & 4,6 \\
Marcas & Centro & 56 & 2,3 \\
Basilicata & Sul & 46 & 1,8 \\
Toscana & Centro & 45 & 1,8 \\
Piemonte & Norte & 43 & 1,7 \\
Calábria & Sul & 42 & 1,7 \\
Outros & - & 108 & 4,4 \\
Total & & $\mathbf{2 . 4 2 2}$ & 100 \\
\hline
\end{tabular}

Fonte: Livros Paroquiais de Registros de Casamentos, 1885-1930.

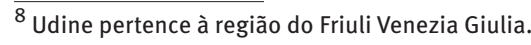


Na década de 1890, outras regiões aderiram à febre emigratória para equilibrar o volume demográfico nos campos. Por exemplo, Lombardia e Emilia-Romanha, no norte, e Abruzo e Lácio, na região central, representam juntas $25 \%$ da população italiana em Franca. Ainda assim, cerca de $75 \%$ dos italianos chegados a Franca eram oriundos do norte da Itália, enquanto as províncias da região central englobavam $15 \%$ dos imigrantes e os meridionais apenas $10 \%$ do total.

0 impacto da imigração atingiu todas as regiões italianas, respondendo às situações históricas que impulsionavam os imigrantes para deixarem seu mercado saturado de trabalho em busca de outro onde pudessem se tornar novamente ativos na América. Acima de tudo, o desejo desse trabalhador era adquirir novamente seu bem-estar, seja nas lavouras de café como pequenos proprietários, seja se deslocando para os núcleos urbanos.

\section{0 mercado matrimonial dos italianos em Franca}

Os cientistas sociais veem o processo de escolha dos cônjuges como um sistema de mercado (LEVY, 2009, p. 117). Em toda a sociedade humana, esse mercado matrimonial tem regras, seja na seleção do cônjuge, na negociação entre famílias, ou na reprodução do grupo e, no caso de imigrantes, envolve a identificação étnica e a disposição em permanecer na terra adotiva (TRUZZI, 2012, p. 171).

É natural que a maioria das crianças e jovens italianas que chegaram no município de Franca adentrasse futuramente no mercado matrimonial local. A moral e os bons costumes da época pressionavam esses nubentes a formalizarem suas uniões de modo a não contrariar a religião católica (BASSANEZI, 2019, p. 171). Embora alguns casais mantivessem uniões consensuais, a imensa maioria desses italianos se casou "perante Deus" e teve seus registros coletados por essa pesquisa.

Entre os italianos imigrados com destino a Franca entre 1885 e 1901, 54,5\% dos homens e $45,4 \%$ das mulheres eram crianças ou jovens com até 20 anos de idade. A proporção de mulheres solteiras era de 1 para cada 1,2 homem. Ou seja, 4,5\% dos homens italianos com menos de 20 anos saídos da Hospedaria de Imigrantes que passaram a residir em Franca teriam de optar por se casar com uma noiva de nacionalidade diferente.

Na Tabela 6, tratamos de dividir o número de imigrantes suscetíveis de entrar no mercado de casamentos local em dois períodos: antes e depois do Decreto Prinetti. Nota-se que, nos 16 anos antecedentes à promulgação do decreto que freou a emigração subvencionada, deslocaram-se três vezes mais italianos do que nos 18 anos seguintes. Além disso, a participação masculina era $5 \%$ maior do que a feminina. 0 peso desses grupos diminuiu a partir do momento em que o governo italiano, por intermédio do Commissariato dell'Emigrazione, passou a controlar a emissão de passaportes para viajantes que não pudessem custear a própria viagem ou que não fossem beneficiados pelos chamados de parentes no Brasil (ALVIM, 1986, p. 59). 
TABELA 6

Imigrantes italianos com menos de 20 anos, por sexo, segundo período de chegada Município de Franca - 1886-1920

\begin{tabular}{lccr}
\hline \multicolumn{1}{c}{ Período } & Homens & Mulheres & Total \\
\hline $1885-1901$ & 966 & 804 & 1.770 \\
$1902-1920$ & 374 & 277 & 651 \\
Total & 1.340 & $\mathbf{1 . 0 8 1}$ & $\mathbf{2 . 4 2 1}$ \\
\hline
\end{tabular}

Fonte: Registros de Matrícula da Hospedaria de Imigrantes de São Paulo.

A escolha matrimonial sempre foi uma preocupação no interior das famílias e o desequilíbrio na entrada de homens italianos nesse mercado refletiu seriamente nas opções tanto do universo masculino quanto do feminino. Historicamente, o deslocamento de homens italianos solteiros sem família para o trabalho nas lavouras cafeeiras paulistas deixou o mercado matrimonial em desequilíbrio (BASSANEZI, 1996; MONSMA; TRUZZI; VILLAS BOAS, 2004). Esse excedente de homens impossibilitou que todos encontrassem uma parceira nascida na Itália e proporcionou mais chances de escolherem mulheres fora do próprio grupo étnico. Em contrapartida, as mulheres, em menor número, tiveram menor oportunidade de se casarem com brasileiros ou homens de outras nacionalidades.

Após o Decreto Prinetti, o contingente feminino foi ainda menos expressivo. As mulheres solteiras correspondiam a $42 \%$ das italianas que se dirigiram ao município estudado, alterando a proporção de 1,2 para 1,35 homem para cada mulher. Esse acréscimo interferiu na intensidade com que se realizavam os casamentos exogâmicos entre os homens italianos, impossibilitados de encontrar uma parceira conjugal dentro do próprio grupo étnico.

Os efeitos do Decreto Prinetti não foram sentidos tão imediatamente no mercado matrimonial, porque a falta de jovens italianos recém-chegados ao país foi suprida pela entrada nesse mercado daqueles que imigraram na infância acompanhados pelos pais nas décadas anteriores. Posteriormente, ainda na mesma década, as escolhas matrimoniais sofreram alterações a partir do momento em que os brasileiros filhos de italianos passaram a compor o leque de escolhas desse mercado. Assim, a escassez de italianos natos foi equilibrada por esse novo contingente que já começa a aparecer nos registros paroquiais e assistiu a um crescimento substancial nas décadas seguintes em resposta às taxas de natalidade entre estes imigrantes.

As fontes analisadas permitiram reconstituir o universo de casamentos realizados no município de Franca, entre 1885 e 1930. Foram formalizadas 2.230 uniões, envolvendo 4.460 cônjuges. Ao todo, 99,5\% (4.439) dos nubentes tiveram suas nacionalidades identificadas. A evolução dos casamentos católicos registrados nesse período pode ser observada no Gráfico 3. A linha superior mostra o volume total de casamentos realizados na Paróquia Nossa Senhora da Conceição e nas capelas das vilas de São José da Bela Vista, Restinga, Ribeirão Corrente, Cristais Paulista e Ponte Nova (atual Jeriquara). ${ }^{9}$

\footnotetext{
${ }^{9}$ Até o final do século XIX apenas a Paróquia Nossa Senhora da Conceição registrava os matrimônios católicos de todo o território. A criação das capelas nos distritos foi acontecendo como resultado do adensamento demográfico nas regiões próximas às fazendas cafeeiras.
} 
GRÁFICO 3

Casamentos católicos do grupo étnico italiano, segundo local de realização Município de Franca - 1885-1930

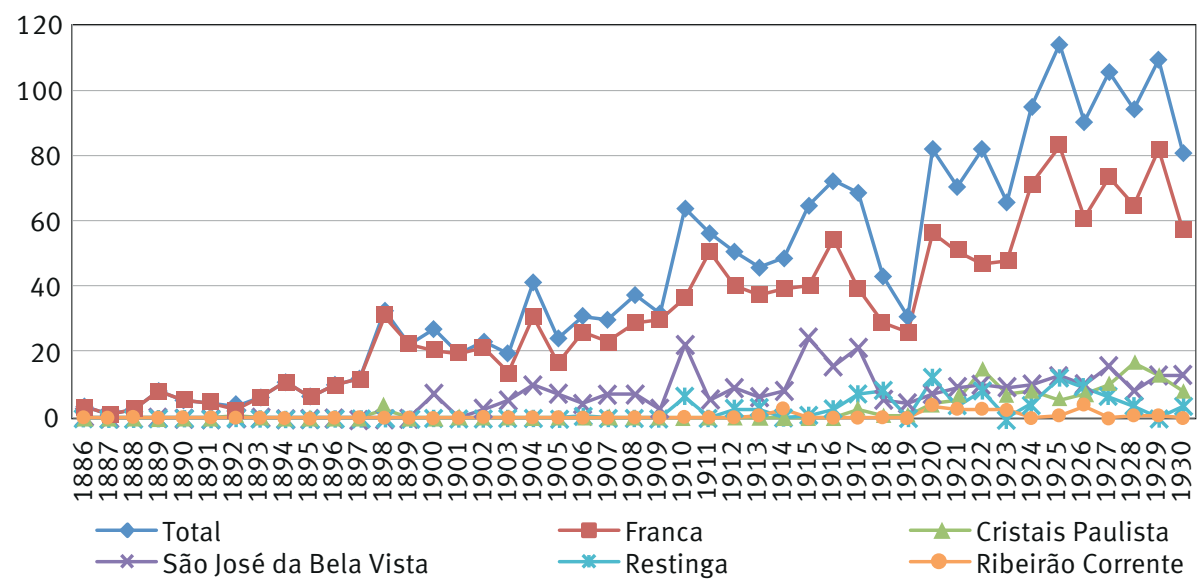

Fonte: Livros Paroquiais de Registros de Casamentos, 1885-1930.

Entre os aspectos mais significativos que podemos analisar, está a crescente ocorrência de casamentos no final do século, rompida pela diminuição relativa no número de novas uniões após a promulgação do Decreto Prinetti em 1902, que restringiu a emigração subsidiada para o Brasil de grupos familiares, com base em denúncias sobre a precária situação em que esses imigrantes se encontravam nas fazendas de café (TRENTO, 1988, p. 50-63). Embora esses imigrantes transoceânicos não olhassem para trás, uma parcela ainda pouco conhecida dessa população retornou à Itália, principalmente em razão dos desgastes físicos e emocionais gerados pelas condições desfavoráveis de trabalho e moradia nas fazendas cafeeiras, que os impediam de conquistar o bem-estar que lhes faltava na terra natal. Esse fluxo temporário acabou por configurar a América também como um mundo alternativo de trabalho, no qual ao cabo de um tempo determinado deixaria de alimentar esperanças de fixação tal como os trabalhadores vênetos estavam acostumados nos países vizinhos, na França, Suíça e Áustria (FRANZINA, 2006, p. 61-134).

É inegável que essas modificações no fluxo imigratório tenham produzido efeitos imediatos na inversão da tendência de crescimento das uniões do grupo étnico no interior paulista. Por exemplo, no ano seguinte à promulgação do Decreto Prinetti, o volume de casamentos foi o menor da década, seguido por uma nova queda em 1905. Podem ser observadas também a diminuição relativa dos casamentos durante a Primeira Guerra Mundial e a retomada do crescimento até a crise de 1929, que levou novamente a uma brusca redução.

Outro fator que influenciou o perfil de uniões foi a substituição nesse mercado de casamentos de italianos natos pelos filhos de italianos, ou seja, pelos ítalo-brasileiros. A restrição da imigração subsidiada reduziu o número de jovens imigrantes dispostos a adentrar no mercado matrimonial que não foi proporcional à quantidade de filhos de italianos 
nascidos no Brasil com idade para se casar. Esse contingente de jovens ítalo-brasileiros só iria adentrar nesse mercado no final da primeira década do século XX, ganhando proporção significativa às vésperas da Primeira Guerra Mundial.

As escolhas nesse mercado de casamentos testemunharam a dinâmica imigratória desses italianos e a manutenção da estrutura familiar deixada no país de origem por meio das altas taxas de endogamia. Com o passar do tempo, a natalidade desse grupo condicionou a manutenção desse padrão e das relações de compromisso entre os filhos de italianos e os compatriotas de seus pais.

A princípio, os homens italianos recorreram às famílias brasileiras para a escolha de suas esposas. Tudo indica que a falta de moças de mesma origem tenha sido o principal obstáculo para a realização de casamentos endogâmicos. A partir de 1888 , passaram a ocorrer casamentos entre parceiros conjugais italianos. De acordo com os dados coletados, até o final do século, foram formalizadas 151 uniões envolvendo nubentes do grupo étnico italiano, contudo, apenas $64,9 \%$ dos registros continham o local de nascimento dos cônjuges. Mesmo assim, é possível aferir que 152 (50,3\%) nubentes escolheram se casar com um conterrâneo, outros 18 (8,9\%) homens italianos se uniram com uma noiva brasileira e apenas quatro (1,3\%) mulheres imigrantes desposaram um brasileiro nos últimos anos do século.

Os estudos de Oswaldo Truzzi (2012) para o município de São Carlos mostram que a falta de mulheres italianas nos primeiros anos de imigração para o município também inibiu um volume maior de uniões endogâmicas. A partir da abolição, o percentual de endogamia masculina manteve-se superior a $80 \%$ por duas décadas. Esse modelo foi menos expressivo em Franca, onde a média dos percentuais de endogamia masculina não ultrapassaram 59\% no mesmo período e revelam uma dificuldade maior em se conseguir uma noiva conterrânea, reflexo da entrada em menor número de crianças e adolescentes italianas para integrarem o mercado matrimonial. Entre 1910 e 1930, a média francana declinou ainda mais, chegando a 13,9\%, enquanto em São Carlos esse percentual não ficou menor que $20 \%$.

A Tabela 7 quantifica a nacionalidade e origem familiar dos nubentes que subiram ao altar na Igreja Matriz de Franca, entre 1885 e $1930 .{ }^{10}$ Os dados mostram que aproximadamente $15 \%$ dos casamentos do grupo étnico italiano envolveram noivos nascidos na Itália. Os valores obtidos revelam que $44,9 \%$ dos homens e $66,7 \%$ das mulheres nascidas na Península Itálica escolheram seu parceiro conjugal no interior do seu grupo nacional. $\mathrm{Na}$ falta de uma parceira conjugal nascida na Itália, a preferência dos italianos recaía sobre as brasileiras (30,9\%), em seguida pelas brasileiras filhas de italianos (20,2\%) e apenas alguns recorreram a um casamento com uma mulher estrangeira de outra nacionalidade $(2,1 \%)$.

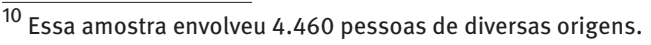


TABELA 7

Casamentos intra e intergrupal entre várias nacionalidades Município de Franca - 1885-1930

\begin{tabular}{lcccccr}
\hline \multicolumn{1}{c}{ Nacionalidade } & Italianos & Brasileiros & $\begin{array}{c}\text { Brasileiros } \\
\text { filhos de } \\
\text { italianos }\end{array}$ & $\begin{array}{c}\text { Outros } \\
\text { estrangeiros }\end{array}$ & $\begin{array}{c}\text { Sem } \\
\text { informação }\end{array}$ & $\begin{array}{c}\text { Total de } \\
\text { mulheres }\end{array}$ \\
\hline Italianas & 319 & 78 & 54 & 18 & 9 & 478 \\
Brasileiras & 220 & - & 476 & - & - & 696 \\
Brasileiras filhas de italianos & 144 & 509 & 333 & 34 & 0 & 1.020 \\
Outras estrangeiras & 15 & - & 8 & - & - & 23 \\
Sem informação & 12 & - & 1 & 0 & - & 13 \\
\hline Total de homens & $\mathbf{7 1 0}$ & $\mathbf{5 8 7}$ & $\mathbf{8 7 2}$ & $\mathbf{5 2}$ & $\mathbf{9}$ & $\mathbf{2}$ \\
\hline
\end{tabular}

Fonte: Livros Paroquiais de Registros de Casamentos, 1885-1930.

No caso das italianas, a proporção de mulheres casadouras nesse mercado matrimonial era ainda mais desproporcional do que o encontrado nos registros de matrícula da Hospedaria de Imigrantes. A proporção de mulheres era de 1 para aproximadamente 1,7 homem, o que facilitava o encontro de cônjuge dentro do seu grupo étnico. A preferência das mulheres que optaram por casar-se fora do grupo nacional era por homens brasileiros $(16,3 \%)$, seguidos por brasileiros filhos de italianos $(11,2 \%)$ e finalmente pelos estrangeiros $(3,7 \%)$. Ainda assim, as mulheres italianas, mais do que os homens, apresentaram uma leve proclividade por se casarem com homens estrangeiros.

Para os filhos de italianos nascidos no Brasil, que substituíram os italianos natos no mercado matrimonial, as uniões com brasileiros foram mais frequentes (52\%) do que com ítalo-brasileiros (35,2\%). Além disso, as mulheres desse contingente também tinham uma tendência maior do que os homens em desposar pessoas de outras nacionalidades. ${ }^{11}$

De acordo com a Tabela 7, os casamentos endogâmicos envolveram 38,1\% dos cônjuges. ${ }^{12}$ Esse percentual engloba os índices de endogamia simples (14,3\%), que corresponde aos casamentos entre cônjuges de mesma nacionalidade, e endogamia oculta (23,8\%), que ocorre quando um cônjuge nascido no Brasil é filho de um pai ou mãe (ou ambos) nascidos na origem enfocada, ou seja, na Itália. Esse fenômeno foi responsável pela manutenção da endogamia entre os italianos durante as primeiras décadas do século XX, devido à queda no número de novos imigrantes.

A aferição da endogamia oculta, que indica a opção por se casar com filhos de compatrícios, contribuiu para realizar uma fotografia mais precisa desse mercado matrimonial e reduzir o risco de uma compreensão equivocada, que poderia atribuir aos italianos uma

\footnotetext{
${ }^{11}$ Apenas oito homens brasileiros filhos de italianos uniram-se a uma estrangeira, enquanto 34 mulheres brasileiras filhas de italianos desposaram um estrangeiro de outra nacionalidade.

${ }^{12} 0$ índice percentual de endogamia foi calculado pela fórmula: $I=2(A+B+A B+B A) / T$.

Onde: $A=$ italianos

$B=$ brasileiros filhos de italianos

$A B=$ italianos com brasileiras filhas de italianos

$\mathrm{BA}=$ brasileiros filhos de italianos com italianas

$\mathrm{T}=$ total da amostra
} 
capacidade maior de inserção em outros grupos graças ao aumento de casamentos destes com brasileiros filhos de italianos.

\section{GRÁFICO 4}

Índices de endogamia

Município de Franca - 1885-1930

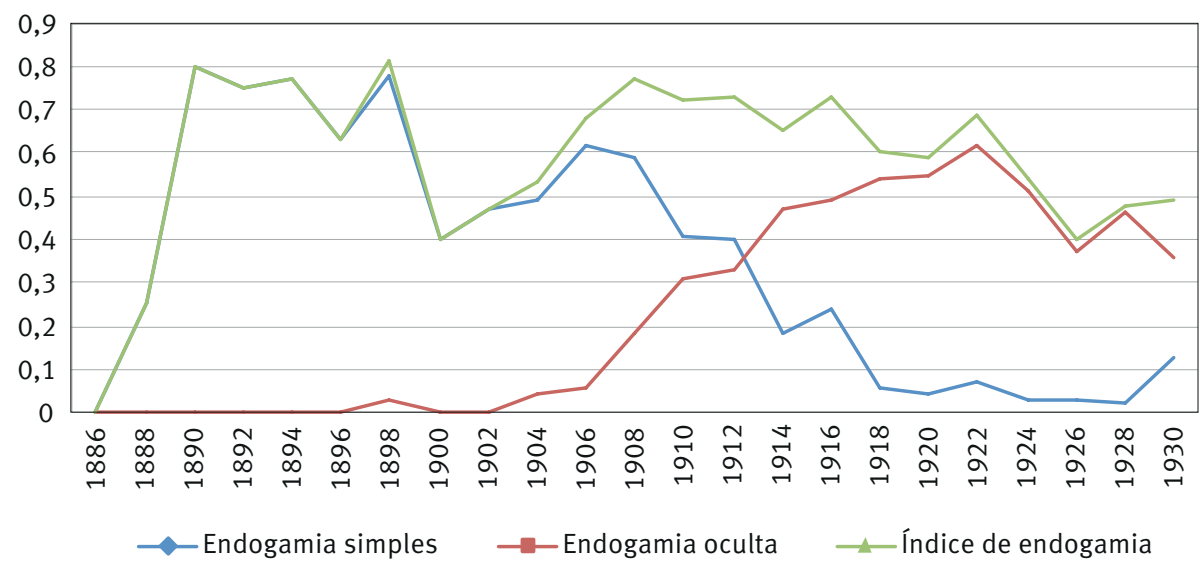

Fonte: Livros Paroquiais de Registros de Casamentos, 1885-1930.

Entre os aspectos mais significativos, como se observa no Gráfico 4, pode-se notar os índices de endogamia desse grupo e suas fases do movimento imigratório italiano. Os picos de endogamia simples coincidem com o período da imigração em massa, enquanto a elevação crescente dos índices de endogamia oculta ocorre a partir da queda na entrada de italianos no município. No período da Primeira Guerra Mundial, os índices endogâmicos sofrem alterações significativas. 0 Gráfico 4 mostra que a endogamia apresentou queda em resposta à diminuição dos italianos natos desde 1906. No entanto, com a entrada da Itália no conflito, muitos imigrantes abandonaram suas expectativas de retorno e resolveram se estabelecer definitivamente no Brasil, refletindo no aumento dos índices de exogamia, principalmente, no pós-guerra. Durante o conflito os percentuais de exogamia variaram de $27 \%$ a $40 \%$, sendo que na década seguinte esses valores oscilaram entre $31 \%$ e $60 \%$. Em todo o Brasil, os italianos que ainda encaravam a imigração como um projeto temporário e buscavam direcionar seus casamentos com parceiros da mesma nacionalidade, aos poucos, acentuaram um processo de integração depois da eclosão da Primeira Guerra (TRENTO, 1988, p. 204).

Os índices de endogamia aqui apresentados mostram que esse fenômeno foi uma tendência que se replicou no território paulista alcançado pela imigração em massa de italianos. Bassanezi (1996) e Truzzi (2012), ao resgatarem aspectos relativos ao comportamento da nupcialidade desses grupos de imigrantes, vislumbraram que a endogamia era favorecida pelos respectivos contextos e bagagens culturais e refletia as condições do processo imigratório por eles vivenciados, ou seja, regulavam-se conforme a organização social do grupo e da própria sociedade hospedeira. 0 espaço social e geográfico 
contribuiu para que a regra da endogamia envolvesse os nubentes no estreito contexto da fazenda cafeeira, de propriedades vizinhas bem próximas ou de outra propriedade onde eventualmente ambos os noivos haviam morado. 0 rumo tomado pelas famílias imigrantes também favorecia o encontro de parceiros da terra de origem e conhecidos no navio ou na Hospedaria no momento da imigração (BASSANEZI, 2019, p. 167-97). Essa sociabilidade reforçava vínculos de amizade e conterraneidade e foi responsável por criar extensas redes entre italianos e seus descendentes, resgatando relacionamentos rompidos ao imigrar e proporcionando frequentemente a realização de vários casamentos no seio de duas famílias.

$\mathrm{O}$ apoio dessa rede familiar possibilitou o encontro de parceiros conjugais de origem conhecida, principalmente pelo fato de a proximidade das casas de colonos facilitar casamentos entre vizinhos, cujas capacidades de trabalho eram conhecidas. Sob essa perspectiva, Maria Sílvia Bassanezi (2019, p. 188) esclarece que, no âmbito da fazenda cafeeira, "o ideal era um homem capaz de labutar de sol a sol no cafezal, na roça de subsistência ou em qualquer outra atividade casar-se com uma mulher prendada, trabalhadeira, econômica, capaz de dar conta de todas as tarefas domésticas" e ainda ajudar no cafezal.

0 emigrante atuava no interior de sua rede de relações pessoais mobilizando recursos para se inserir no mercado de trabalho na sociedade receptora, além de também representar um papel de agente mobilizador de seu capital social (TRUZZI, 2008, p. 207). Em muitos casos, os contatos pessoais definiam as escolhas do mercado matrimonial mediante comunicações e favores entre famílias, amigos e paesani. ${ }^{13}$ No caso dos italianos na Argentina, Samuel Baily (2003) analisou a imigração de um grupo de italianos da comuna de Agnone, na região do Molise, para Buenos Aires, com resultados similares aos encontrados por nossa pesquisa em Franca para os vênetos de Rovigo, os lombardos de Bérgamo e os abruzenses de Chieti.

A origem familiar italiana atuou como condicionante significativo das opções matrimoniais durante todo o período estudado; porém, com o decorrer do tempo e a diminuição desse contingente populacional, tais preferências naturalmente foram se diluindo. Uma constatação evidente é que o ambiente e as condições de vida desses imigrantes na terra adotiva condicionavam tendências endogâmicas e exogâmicas. No mundo urbano, a crescente ocorrência de casamentos exogâmicos aponta para a diminuição da dependência da estrutura familiar e o aumento da escolha pessoal e afetiva. Os dados obtidos para Franca mostram que os imigrantes que se inseriam definitivamente no mundo urbano protagonizaram mais casamentos exogâmicos, em intensidade e ritmo diferentes. Por exemplo, alguns italianos de destaque nas atividades comerciais conseguiam romper as barreiras da elite local para realizar casamentos com membros dessa vida urbana. Diferentemente, no meio rural, onde a imigração ainda era vista como um projeto temporário, escolher o marido ou a mulher entre os colonos de mesma origem

\footnotetext{
$\overline{13}$ Lançamos mão do conceito de paesani para definir os conterrâneos de um mesmo paese, ou aldeia. 0 conceito se adequa à realidade dos contatos pessoais dos italianos na sociedade receptora por meio da busca de pessoas conhecidas ou de procedência geográfica comum.
} 
era uma forma de facilitar um possível retorno à Itália. A família italiana impunha aos filhos a endogamia como projeto coletivo e inibia os casamentos interétnicos, causando resistência e disputas entre pais e filhos. ${ }^{14}$

A temática das redes na pauta das práticas endogâmicas retoma a discussão sobre a difusão da imigração no estado de São Paulo conforme as áreas geográficas atingidas pelo êxodo italiano. No final do século XIX, o pensamento emigrantista da região do Vêneto estava convencido de que era necessário emigrar um grande número de pessoas para se encontrarem na América e "prestar reciprocamente ajuda e constituir entre eles uma boa vizinhança de gente laboriosa, ordenada e apta a progredir” (FRANZINA, 2006, p. 425).

Os estudos de Bassanezi na fazenda Santa Gertrudes, na região de Rio Claro, corroboram o argumento de que a origem geográfica influenciava o mercado matrimonial dos trabalhadores estrangeiros, principalmente italianos e espanhóis, que procuravam "pessoas provenientes do mesmo local na terra de origem, pessoas que haviam emigrado juntas ou que haviam seguido logo depois os passos de famílias que viajaram antes" (BASSANEZI, 2019, p. 176), reforçando laços preexistentes de compadrio e amizade entre duas ou mais famílias.

O estudo das famílias italianas formadas em Franca mostrou um volume considerável de uniões conjugais entre paesani, ou seja, oriundos da mesma aldeia ou região próxima. Esse fenômeno permitiu a reprodução de um tipo de sociedade camponesa aos moldes da região do Vêneto do fim do século XIX - "tradicionalista e católica" (FRANZINA, 2006, p. 412) -, culminando na cristalização de modelos culturais no decorrer do tempo em várias áreas brasileiras. Por exemplo, entre os italianos nascidos em Rovigo que se casaram com italianas, a endogamia provincial foi protagonizada em 43,6\% dos casos. Entre os vênetos e abruzenses, mais de um terço dos homens recorreram a noivas da mesma região (aproximadamente $33 \%$ e $39 \%$, respectivamente), sem contar a preferência dos noivos naturais do Abruzo por nubentes da região vizinha do Molise. Entre os naturais da Lombardia, um quarto dos nubentes nascidos em Bergamo recorreram a uma noiva nascida na mesma província. Os resultados apurados mostram que, embora a origem comum fosse privilegiada para a escolha dos cônjuges, os casamentos consanguíneos eram raros.

Nesse sentido, era comum noivos cruzarem o Atlântico para concretizarem pedidos de casamentos realizados antes da emigração. A concentração maciça de paesani numa mesma localidade, as redes familiares e os laços de amizade contribuíam para o deslocamento de pessoas casadouras na Itália a fim de unirem-se em matrimônio nas terras paulistas. 0 cruzamento de fontes evidencia esse comportamento ao revelar registros de jovens contraindo matrimônio com conterrâneos poucos dias ou meses depois de entrarem no país.

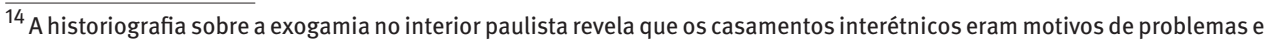
oposição em muitas famílias italianas no Brasil. Inquéritos e processos criminais de defloramento mostram casos extremos de jovens italianos que enfrentaram a resistência dos pais e da comunidade à exogamia (MONSMA; TRUZZI; VILLAS BOAS, 2004)
} 
Em Franca, como em outras áreas de recebimento significativo de imigrantes, o declínio da imigração estrangeira contribuiu de maneira importante para a reformulação desse mercado matrimonial. Além disso, os laços de origem tornam-se com o tempo mais distantes, refletindo na queda dos índices de endogamia a partir do final desse meio século transcorrido entre as décadas de 1880 e 1930.

\section{Considerações finais}

A metodologia de reconstituição de famílias a partir de fontes paroquiais, combinada ao cruzamento dos registros de imigração, oferece diversas potencialidades tanto para análises quantitativas quanto para estudos sobre trajetórias individuais e redes de imigrantes. No nosso caso, a identificação dessa população ítalo-brasileira por meio do método onomástico contribuiu para análises empíricas originais sobre as famílias imigrantes na localidade explorada entre 1885 e 1930, comparáveis a outros grupos italianos que se destinaram ao estado de São Paulo.

0 estudo sobre a nupcialidade da comunidade italiana em Franca permitiu conhecer características do êxodo dos italianos para o Brasil que refletiram sobre a nupcialidade, tais como as épocas de atração de imigrantes, o perfil desses grupos e suas estratégias de alianças e reprodução social. Os aspectos demográficos desses italianos revelam características distintas ao período de imigração que condicionavam as relações entre família e trabalho para a sobrevivência e adaptação do grupo no novo ambiente.

Essa pesquisa reforça ainda os estudos sobre a nupcialidade de indivíduos de origem imigrante no interior de São Paulo, que indicam altas taxas de endogamia para as primeiras duas gerações de imigrantes até a Grande Depressão no final dos anos 1920. Verificamos que a nupcialidade era uma preocupação da maioria das famílias italianas, na qual o parceiro a ser escolhido deveria se enquadrar nos objetivos familiares de trabalho, recaindo sobre pessoas conhecidas. Essa característica reforçava vínculos de amizade e conterraneidade responsáveis por criar extensas redes entre italianos e seus descendentes, sustentadas pelos intensos fluxos imigratórios e a concentração de pessoas ligadas a uma mesma região de origem.

\section{Referências}

ALVIM, Z. Brava gente! Os italianos em São Paulo. São Paulo: Brasiliense, 1986.

BAILY, S. La cadena migratória de los italianos em la Argentina. In: BOUCAULT, C. E. A.; MALATIAN, T. M. (org.). Políticas migratórias: fronteiras dos direitos humanos no século XXI. Rio de Janeiro; São Paulo: Renovar, 2003.

BASSANEZI, M. S. B.; SCOTT, A. S. V.; BACELLAR, C. A. P.; TRUZZI, O. M. S. Atlas da imigração internacional em São Paulo - 1850-1950. São Paulo: Editora Unesp, 2008.

BASSANEZI, M. S. B. Colonos do café. São Paulo: Contexto, 2019. 
BASSANEZI, M. S. B. Os eventos vitais na reconstituição da história. In: PINSKY, C. B.; DE LUCA, T. R. (org.). $O$ historiador e suas fontes. São Paulo: Contexto, 2009. p. 141-172.

BASSANEZI, M. S. B. Sposàrsi nel Brasile. Alguns aspectos da nupcilidade entre imigrantes italianos em terras paulistas. In: DE BONI, L. A. (org.). A presença italiana no Brasil. Porto Alegre: Edições Est, v. 3, 1996.

BLOCH, M. Apologia da história - ou o ofício do historiador. São Paulo: Zahar, 2002.

BOUCAULT, C. E. A.; MALATIAN, T. M. Políticas migratórias: fronteiras dos direitos humanos no século XXI. Rio de Janeiro; São Paulo: Renovar, 2003.

CINTRA, R. A. Italianos em Ribeirão Preto-SP: família e nupcialidade (1890-1900). In: XXII SIMPÓSIO NACIONAL DE HISTÓRIA. Anais [...]. João Pessoa: Associação Nacional de História (ANPUH), 2003.

DE BONI, L. A. (org.). A presença italiana no Brasil. Porto Alegre: Edições Est, v. 3, 1996.

DI GIANNI, T. P. Italianos em Franca: imigrantes de boa estrela numa cidade do interior. Franca: Unesp/FDHSS, 1997.

FAUSTO, B. Fazer a América: a imigração em massa para a América Latina. São Paulo: Edusp, 2000.

FRANZINA, E. A grande emigração: o êxodo dos italianos do Vêneto para o Brasil. Campinas: Editora da Unicamp, 2006.

GINZBURG, C.; CASTELNUOVO, E.; PONI, C. A micro-história e outros ensaios. Rio de Janeiro: Bertrand Brasil, 1989.

GINZBURG, C. O nome e o como. Troca desigual e mercado historiográfico. In: GINZBURG, C.; CASTELNUOVO, E.; PONI, C. A micro-história e outros ensaios. Rio de Janeiro: Bertrand Brasil, 1989. p. 169-178.

HENRY, L. Técnicas de análise em demografia histórica. Curitiba: Universidade Federal do Paraná, 1977.

HOLLOWAY, T. Imigrantes para o café. Rio de Janeiro: Paz e Terra, 1984.

LEVY, M. S. F. A escolha do cônjuge. Revista Brasileira de Estudos de População, v. 26, n. 1, p. 117-133, 2009.

LEVY, M. S. F.; SCARANO, J. O imigrante em São Paulo: casamento e nupcialidade. População e Família, v. 2, p. 61-74, 1999.

MARCÍLIO, M. L. Crescimento demográfico e evolução agrária paulista: 1700-1836. São Paulo: Hucitec, 2000.

MONSMA, K.; TRUZZI, O.; VILLAS BOAS, S. Entre a paixão e a família: casamentos interétnicos de jovens italianos no oeste paulista, 1890-1914. In: XIV ENCONTRO NACIONAL DE ESTUDOS DE POPULAÇÃO. Anais [...]. Caxambu: Abep, 2004.

PINSKY, C. B.; DE LUCA, T. R. (org.). O historiador e suas fontes. São Paulo: Contexto, 2009.

RETTAROLI, R. Age at marriage in ineteenth century Italy. Journal of Family History, v. 15, n. 4, 1990.

RODARTE, M. M. S. 0 trabalho do fogo: perfis de domicílios enquanto unidades de produção e reprodução nas Minas Gerais oitocentista. Tese (Doutorado) - Universidade Federal de Minas Gerais (UFMG), Belo Horizonte, 2008.

TRENTO, A. Do outro lado do Atlântico: um século de imigração italiana no Brasil. São Paulo: Nobel, 1988. 
TRUZZI, O. Italianidade no interior paulista: percursos e descaminhos de uma identidade étnica (1880-1950). São Paulo: Editora Unesp, 2016.

TRUZZI, O. Padrões de nupcialidade na economia cafeeira de São Paulo (1860-1930). Revista Brasileira de Estudos de População, v. 29, n. 1, p. 169-189, 2012.

TRUZZI, O. Redes em processos migratórios. Tempo Social: Revista de Sociologia da USP, v. 20, n. 1, 2008.

\title{
Sobre 0 autor
}

José Victor Maritan Gonçalves é doutorando e mestre em História e Cultura Social pelo Programa de Pós-graduação em História da Universidade Estadual Paulista "Júlio de Mesquita Filho" (Unesp).

\section{Endereço para correspondência}

Rua Corifeu de Azevedo Marques, 574, Jardim Califórnia

14405-302 - Franca-SP, Brasil

\begin{abstract}
Sposàrsi a Franca: nuptial trends among Italian immigrants in the interior of São Paulo, 18851930

In line with studies in Demographic History and Family History, this article aims to rescue aspects related to nuptiality experienced by Italians and their descendants in the municipality of Franca, in the interior of the state of São Paulo. The reflection is corroborated by recent historiography research pointing to the expansion of the coffee-based economy in the interior of São Paulo as responsible for demographic changes through the attraction of mass international immigration. This affected different areas, including family, matrimonial relations, ethnicity and integration of these groups in Brazilian society at the turn of the 20th century. A combination of serial and microanalysis methodologies to explore the data available in the registration records of the São Paulo Immigrant Inn and wedding seats in the Parish Records of the Diocesan Archive of Franca (1885-1930), paves the way to expand the universe of interpretations on nuptiality in municipalities affected by Italian immigration. This article examines the impacts of immigration variables on Italians' marriage patterns in the municipality and retrieves aspects of this groups' inbreeding, favored by the respective cultural contexts and backgrounds that led to the immigration process they experienced.
\end{abstract}

Keywords: Immigration. Nuptiality. Microhistory. 


\section{Resumen}

Sposàrsi a Franca: tendencias de la nupcialidad entre inmigrantes italianos en el interior de São Paulo, 1885-1930

En línea con los estudios en Demografía histórica e Historia familiar, este artículo tiene como objetivo rescatar aspectos relacionados con la nupcialidad vivida por los italianos y sus descendientes en el municipio de Franca, en el interior del estado de San Pablo. La reflexión es corroborada por la historiografía reciente, que apunta a la expansión de la economía cafetera en el interior del estado como responsable de cambios en el panorama demográfico mediante la atracción de la inmigración internacional masiva, cuyos impactos se sintieron en diferentes espacios de acción, en la familia, en las relaciones matrimoniales, en la etnicidad y en la integración de estos grupos en la sociedad brasileña entre fines del siglo XIX y las primeras décadas del XX. Al combinar metodologías seriadas y de microanálisis para explorar los datos disponibles en los registros de la Posada de Inmigrantes de San Pablo y en los asientos de boda del Registro Parroquial del Archivo de la Curia Diocesana de Franca (1885-1930) se abre el camino para enriquecer el universo de interpretaciones sobre nupcialidad en los municipios afectados por la inmigración internacional de italianos. Este artículo examina los impactos de las variables de inmigración en los patrones matrimoniales de los italianos en el municipio y recupera aspectos de la endogamia de este grupo, favorecida por los respectivos contextos culturales y antecedentes que llevaron al proceso de inmigración que vivieron.

Palabras clave: Inmigración. Nupcialidad. Microhistoria.

Recebido para publicação em:26/10/2020 Aceito para publicação em 29/06/2021 